\section{MERS Coronavirus in Dromedary Camel Herd, Saudi Arabia}

\section{Maged G. Hemida, ${ }^{1}$ Daniel K.W. Chu, ${ }^{1}$ Leo L.M. Poon, Ranawaka A.P.M. Perera, Mohammad A. Alhammadi, Hoi-yee Ng, Lewis Y. Siu, Yi Guan, Abdelmohsen Alnaeem, and Malik Peiris}

A prospective study of a dromedary camel herd during the 2013-14 calving season showed Middle East respiratory syndrome coronavirus infection of calves and adults. Virus was isolated from the nose and feces but more frequently from the nose. Preexisting neutralizing antibody did not appear to protect against infection.

$\mathrm{O}$ ngoing transmission of Middle East respiratory syndrome coronavirus (MERS-CoV) to humans underscores the need to understand the animal sources of zoonotic infection $(1,2)$. MERS-CoV RNA has been detected in dromedary camels $(3,4)$, and dromedary infection precedes human infection (5). We conducted a prospective study in dromedary herds in Al-Hasa, Saudi Arabia, through the peak calving season (December 2013-February 2014) to document virologic features of MERS-CoV infection in these animals.

\section{The Study}

We studied dromedaries at 2 farms in Al-Hasa, 4-5 $\mathrm{km}$ apart. Farm A had 70 animals; 4 were 1 month of age, 8 were $\approx 1$ year of age, and the rest were adults $(\geq 2$ years of age). The herd did not go to pasture in the desert ("zero-grazing"; type of grazing may influence types of potential exposures). The animals were sampled on 5 occasions during November 2013-February 2014. Farm B ("semi-zero-grazing") had 17 adults and 3 calves; its herd was sampled in February 2014. Nasal, oral, or rectal swab samples and blood samples were collected (Table 1; online Technical Appendix Table, http://wwwnc.cdc.gov/ EID/article/20/7/14-0571-Techapp1.pdf). Swab and serum samples were stored frozen at $-80^{\circ} \mathrm{C}$ until testing.

Author affiliations: King Faisal University, Al Hofuf, Saudi Arabia (M.G. Hemida, M.A. Alhammadi, A. Alnaeem); Kafrelsheikh University, Kafr Elsheikh, Egypt (M.G. Hemida); and The University of Hong Kong, Hong Kong, China (D.K.W. Chu, L.L.M. Poon, R.A.P.M. Perera, H.-y. Ng, L.Y. Siu, Y. Guan, M. Peiris)
Hydrolysis probe-based real-time reverse transcription PCR (RT-PCR) targeting MERS-CoV upstream of $\mathrm{E}(\mathrm{UpE})$ and open reading frame (ORF) 1a genes and a broad-range RT-PCR reacting across the $\mathrm{CoV}$ family to detect other CoVs were used as described (4). Specimens initially positive for MERS-CoV were re-extracted and retested to confirm the positive results.

The full genome of MERS-CoV was obtained directly from the clinical specimens with 3-4 times coverage by sequencing PCR amplicons with overlapping sequence reads and sequence assembly (4). Dromedary MERS-CoV full genomes obtained in this study (GenBank accession nos. KJ650295-KJ650297) were aligned with human MERS$\mathrm{CoV}$ genomes retrieved from GenBank. We constructed full-genome phylogenies using MEGA5 with neighborjoining and bootstrap resampling of 500 replicates (6). Virus isolation was attempted in Vero E6 cells. We tested serum samples for neutralizing antibody titers using a validated MERS-CoV spike pseudoparticle neutralization test (7) (online Technical Appendix).

At farm A, we detected MERS-CoV in 1 of 4 dromedaries sampled on November 30, none of 11 sampled on December 4, nine of 11 sampled on December 30, and none of 9 sampled on February 14 (Table 1). Of the 10 dromedaries that tested positive for MERS-CoV, 9 had parallel nasal and fecal specimens tested, with virus detected in the nasal swab specimens from 8 and the fecal specimen from 1. At the December 30 sampling, 7 of 8 calves and 2 of 3 adults tested positive for MERS-CoV, indicating that when MERS-CoV circulates on a farm, both calves and adults can be infected (online Technical Appendix Table). Because all 12 adults with serum collected before December 30 were seropositive (titers $\geq 320$ ), it is likely, though not certain, that the MERS-CoV infections in the 2 adults (nos. 21, 19Dam) sampled on December 30 were reinfections, as has been reported for other CoVs (8). The seronegative 1-year-old calves, nos. 13 and 14, had the highest nasal viral loads (UpE assay $1.3 \times 10^{8}$ to $1.78 \times 10^{8} / \mathrm{mL}$ specimen), and a 2-week-old calf, no. 22, with (presumably passively acquired) titers of 1,280 became infected but had a much lower viral load. Overall, these data suggest that prior infection or passively acquired maternal antibody might not provide complete protection from infection (online Technical Appendix Table).

Four MERS-CoV-positive calves had mild respiratory signs (cough, sneezing, respiratory discharge), abnormally elevated body temperature, and loss of appetite at the December 30 sampling, which resolved over a few days. Three calves from which paired serum samples were available (Table 2; nos. 13, 15, 17) demonstrated $\geq 4$-fold rising antibody titers to MERS-CoV. Calf no. 13 (1 year of age) had 
Table 1. RT-PCR of dromedary camel samples for MERS-CoV, Al-Hasa, Saudi Arabia*

\begin{tabular}{ccccc}
\hline & & \multicolumn{3}{c}{ No. specimens } \\
& Aget/no. & \multicolumn{3}{c}{ positive/no. tested } \\
\cline { 3 - 5 } Farm, sampling date & sampled & Nasal & Oral & Fecal \\
\hline Farm A & & & & \\
2013 Nov 30 & Calf, 0 & ND & ND & ND \\
& Adult, 4 & $1 / 1$ & $0 / 2$ & $0 / 4$ \\
2013 Dec 4 & Calf, 9 & ND & $0 / 9$ & $0 / 7$ \\
& Adult, 2 & ND & $0 / 2$ & $0 / 2$ \\
2013 Dec 30 & Calf, 8 & $7 / 8$ & $0 / 1$ & $0 / 6$ \\
& Adult, 3 & $1 / 3 \ddagger$ & 0 & $1 / 3 \ddagger$ \\
2014 Feb 14 & Calf, 7 & $0 / 7$ & ND & $0 / 7$ \\
& Adult, 2 & $0 / 2$ & ND & $0 / 2$ \\
\hline Farm B: 2014 Feb 11 & Calf, 3 & $0 / 3$ & ND & $0 / 3$ \\
& Adult, 3 & $0 / 3$ & ND & $0 / 3$ \\
\hline
\end{tabular}

${ }^{*}$ Data on individual dromedaries are provided in online Technical Appendix Table, http://wwwnc.cdc.gov/EID/article/20/7/14-0571-Techapp1.pdf. RT$\mathrm{PCR}$, reverse transcription PCR; MERS-CoV, Middle East respiratory syndrome coronavirus; ND, not done.

†Adults are $6-14 \mathrm{y}$ of age; calves are $40 \mathrm{~d}$ to $2 \mathrm{y}$ of age.

$\ddagger$ Two different dromedaries were positive in nasal and fecal swabs.

a high viral load and was seronegative at the first MERSCoV-positive result (indicating that it had been recently infected) but was MERS-CoV RNA negative 6 weeks later, suggesting that virus shedding is not prolonged. We did not detect virus RNA by RT-PCR in the 3 acute-phase serum samples from infected dromedaries (nos. 1, 16, 17), suggesting that acute infection is not associated with prolonged viremia. Dromedaries from farm B were sampled once on February 11; all results were negative.

The full genomes of MERS-CoV sequenced directly from a nasal swab specimen collected on November 30 were identical to those from a nasal swab specimen and a fecal specimen collected on December 30. In addition, the complete spike gene was sequenced from 4 other MERS$\mathrm{CoV}$-positive nasal swab specimens, and these spike genes were genetically identical.

Virus isolation in Vero E6 cells was attempted from 7 positive nasal swab and fecal specimens that had $>10^{6}$ copies/mL in the original sample in the UpE RT-PCR. Viruses were isolated from 2 nasal swab (nos. 13, 14) and 1 fecal swab (no. 19Dam) specimens collected on December 30; these were the specimens with high numbers of MERS-CoV copies $\left(9.27 \times 10^{7}\right.$ to $1.78 \times 10^{8}$ copies/ $\mathrm{mL})$. The full-genome sequence of 1 virus culture isolate was obtained in parallel with that of the original virus in the original clinical specimen. We observed 3 nucleotide changes in ORF1b, spike, and membrane protein genes in the isolates after 2 passages in Vero E6 cells, of which 2 were nonsynonymous, leading to changes in spike (S1251F) and membrane proteins (T8I). This finding highlights the importance of sequencing the viral genome directly from clinical specimens.

MERS-CoVs circulating in dromedaries on farm A during a 1-month period were genetically identical over the full 30,100-nt genome in 3 viruses and the spike protein of
4 more viruses, giving a mutation rate of $0 \mathrm{nt}$ substitutions per site per day $\left(95 \%\right.$ credible interval 0 to $\left.2.7 \times 10^{-6}\right)$. The estimated mutation rate for epidemiologically unlinked human MERS-CoV was $3.1 \times 10^{-6}\left(95 \%\right.$ CI $2.4 \times 10^{-6}$ to 3.8 $\left.\times 10^{-6}\right)(9)$.

\section{Conclusions}

The unusual genetic stability of MERS-CoV in dromedaries, taken together with its high seroprevalence $(7,10-13)$, raises the hypothesis that dromedaries might be the natural host for this virus. Further longitudinal studies of MERS-CoVs in dromedaries are needed to confirm this hypothesis.

Genome organization of the dromedary MERS-CoV detected in this study was identical to that of the virus in humans. The virus strains clustered phylogenetically within clade B (9) and were most closely related to the strain MERS-CoV_FRA/UAE and to MERS-CoV detected in Buraidah (Saudi Arabia) and Al-Hasa (Figure). The farm is $\approx 300 \mathrm{~km}$ from United Arab Emirates and $600 \mathrm{~km}$ from Buraidah. Dromedaries move between Al-Hasa and Buraidah and, more limitedly, between Al-Hasa and United Arab Emirates.

The full-genome sequence of MERS-CoV from dromedaries in this study is $99.9 \%$ similar to genomes of human clade B MERS-CoV. The spike gene is the major determinant for virus host specificity. In comparison with other publically available human MERS-CoV sequences, we found 6-nt mutations in the spike gene unique to these dromedary viruses. Of these, 3 (S457G, L773F, and V810I) were nonsynonymous. These amino acid changes are located outside the binding interface between MERS-CoV spike protein and human DPP4 receptor, suggesting these amino acid differences are unlikely to affect receptor binding. Thus, these dromedary viruses may retain capacity to infect humans, as Chu et al. suggested for dromedary MERS-CoV in Egypt (4).

MERS-CoV may be isolated from nasal swab specimans and feces, indicating that both could be possible sources of virus transmission to humans and other animals, but virus detection rates were higher in nasal swab specimens.

\begin{tabular}{|c|c|c|c|c|}
\hline \multicolumn{5}{|c|}{$\begin{array}{l}\text { Table 2.Longitudinal sampling of MERS-CoV-positive dromedary } \\
\text { camel calves on farm A, Al-Hasa, Saudi Arabia* }\end{array}$} \\
\hline & Sample collection & & RT-PCR & \\
\hline Calf no. & date & Sex/age & result & Titer \\
\hline \multirow[t]{2}{*}{13} & 2013 Dec 30 & $F / 1 y$ & Positive & $<20$ \\
\hline & 2014 Feb 14 & $F / 1 y$ & Negative & 640 \\
\hline \multirow[t]{2}{*}{15} & 2013 Dec 30 & $F / 1 y$ & Positive & 20 \\
\hline & 2014 Feb 14 & $F / 1 y$ & Negative & 160 \\
\hline \multirow[t]{2}{*}{17} & 2013 Dec 30 & $\mathrm{~F} / 40 \mathrm{~d}$ & Positive & 80 \\
\hline & 2014 Feb 14 & $\mathrm{~F} / 3 \mathrm{mo}$ & Negative & 1,280 \\
\hline \multirow[t]{2}{*}{19} & 2013 Dec 30 & $F / 1 y$ & Positive & NA \\
\hline & 2014 Feb 14 & $F / 1 y$ & Negative & 320 \\
\hline
\end{tabular}




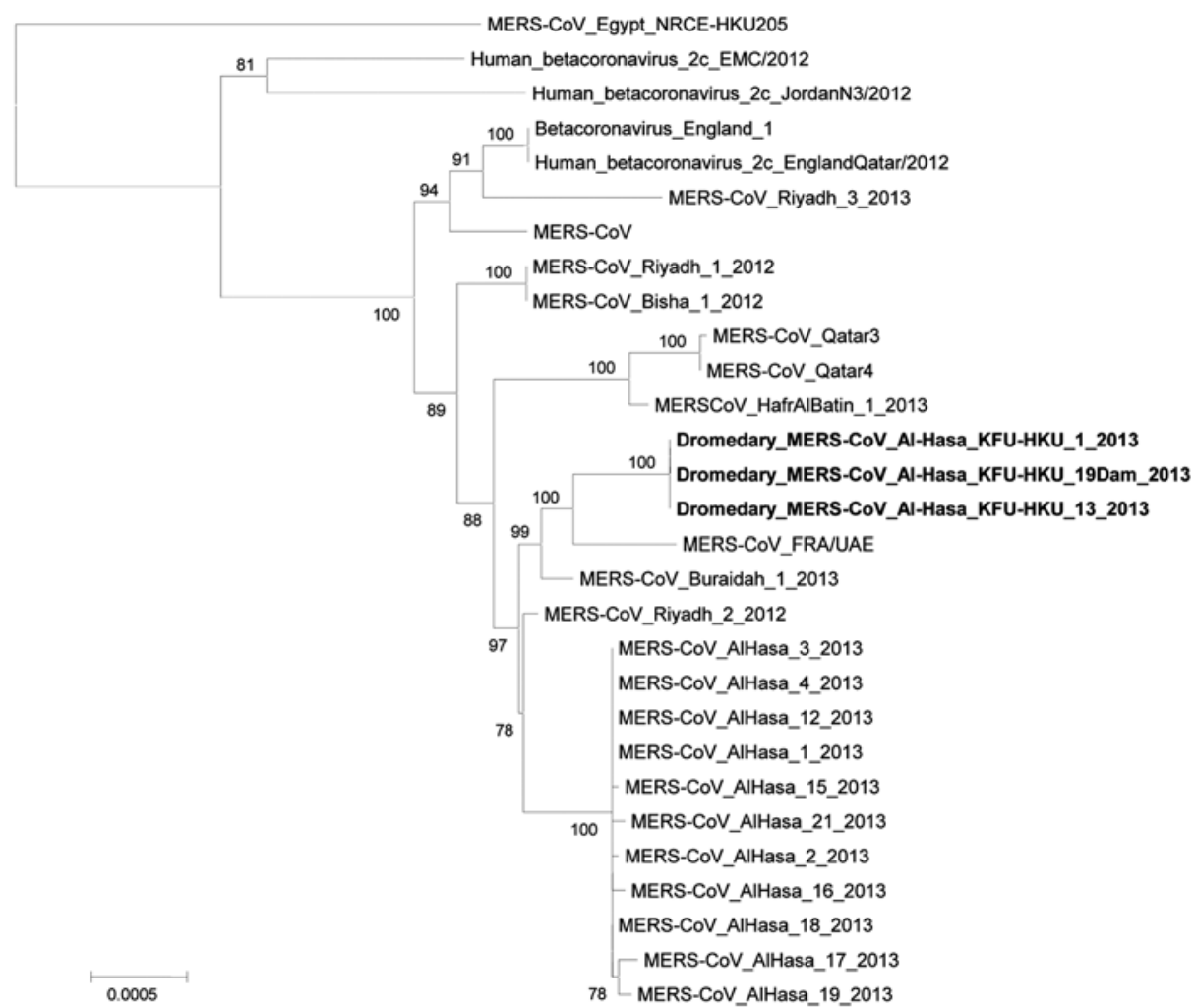

Figure. Phylogenetic tree of Middle East respiratory syndrome coronavirus (MERS-CoV) full genomes $(29,901 \mathrm{nt}$ after trimming the ends) or near-full genomes from humans and dromedary camels. The tree was constructed by using neighbor-joining methods with bootstrap resampling of 500 replicates. The most divergent MERS-CoV, Egypt NRCE-HKU205, was used as outgroup. Bold type indicates camel MERS-CoV genomes from this study. GenBank accession numbers of genome sequences included in this study are KJ477102, KF600652, KF600630, KF600651, KF186567, KF600627, KF186564, KF600634, KF600632, KF600644, KF600647, KF600645, KF186565, KF186566, KF745068, KF600620, KF600612, KC667074, KC164505, KF192507, KF600613, KF600628, KF961222, KF961221, KC776174, and JX869059. Scale bar indicates nucleotide substitutions per site.
Our preliminary data suggest that preexisting MERS-CoV antibody might not completely protect against re-infection; however, this question needs more investigation.

We thank the King Faisal University Deanship of Scientific Research for their support (grant no. 143011). This research was funded by a research contract from the National Institute of Allergy and Infectious Diseases, National Institutes of Health (contract no. HHSN266200700005C), and a grant from the European Community Seventh Framework Program (FP7/2007-2013) under project European Management Platform for Emerging and Re-emerging Disease entities (grant agreement no. 223498) (EMPERIE).

Dr Hemida is an assistant professor of molecular virology at King Faisal University, Saudi Arabia. His primary research interests are virus-host interactions and the molecular biology of CoVs.

\section{References}

1. World Health Organization. Middle East respiratory syndrome coronavirus (MERS-CoV). Summary and literature update-as of 27 March 2014 [cited 2014 Apr 11]. http://www.who.int/csr/disease/ coronavirus_infections/MERS_CoV_Update_27_March_2014. pdf?ua $=1$

2. The WHO MERS-CoV Research Group. State of knowledge and data gaps of Middle East respiratory syndrome coronavirus (MERSCoV) in humans. PLoS Curr. 2013;5:pii:ecurrents.outbreaks.0bf719 e352e7478f8ad85fa30127ddb8.
3. Alagaili AN, Briese T, Mishra N, Kapoor V, Sameroff SC, de Wit E, et al. Middle East respiratory syndrome coronavirus infection in dromedary camels in Saudi Arabia. MBio. 2014;5:e00884-14. http://dx.doi.org/10.1128/mBio.01002-14

4. Chu DKW, Poon LLM, Gomaa MM, Shehata MM, Perera RA, Zeid DA, et al. MERS coronaviruses in dromedary camels, Egypt. [Internet]. Emerg Infect Dis. 2014 Jun [cited 2014 Mar 31].

5. Memish ZA, Cotton M, Meyer B, Watson SJ, Alsahafi AJ, Al Rabeeah AA, et al. Human infection with MERS coronavirus after exposure to infected camels, Saudi Arabia, 2013. [Internet]. Emerg Infect Dis. 2014. http://dx.doi.org/10.3201/ eid2006.140402

6. Tamura K, Peterson D, Peterson N, Stecher G, Nei M, Kumar S. MEGA5: molecular eevolutionary genetics analysis using maximum likelihood, evolutionary distance, and maximum parsimony methods. Mol Biol Evol. 2011;28:2731-9. http://dx.doi.org/10.1093/ molbev/msr121

7. Perera RA, Wang P, Gomaa MR, El-Shesheny R, Kandeil A, Bagato $\mathrm{O}$, et al. Seroepidemiology for MERS coronavirus using microneutralisation and pseudoparticle virus neutralisation assays reveal a high prevalence of antibody in dromedary camels in Egypt, June 2013. Euro Surveill. 2013;18:20574.

8. Addie DD, Dennis JM, Toth S, Callanan JJ, Reid S, Jarrett O. Long-term impact on a closed household of pet cats of natural infection with feline coronavirus, feline leukaemia virus and feline immunodeficiency virus. Vet Rec. 2000;146:419-24. http://dx.doi. org/10.1136/vr.146.15.419

9. Cotten M, Watson SJ, Zumla AI, Makhdoom HQ, Palser AL, Ong SH, et al. Spread, circulation, and evolution of the Middle East respiratory syndrome coronavirus. MBio. 2014;5:e01062-13. http://dx.doi.org/10.1128/mBio.01062-13

10. Reusken CB, Haagmans BL, Müller MA, Gutierrez C, Godeke GJ, Meyer B, et al. Middle East respiratory syndrome coronavirus 
neutralising serum antibodies in dromedary camels: a comparative serological study. Lancet Infect Dis. 2013;13:859-66. http://dx.doi. org/10.1016/S1473-3099(13)70164-6

11. Reusken CB, Ababneh M, Raj VS, Meyer B, Eljarah A, Abutarbush S, et al. Middle East respiratory syndrome coronavirus (MERS-CoV) serology in major livestock species in an affected region in Jordan, June to September 2013. Euro Surveill. 2013;18:20662.

12. Hemida MG, Perera RA, Wang P, Alhammadi MA, Siu LY, Li M, et al. Middle East respiratory syndrome (MERS) coronavirus seroprevalence in domestic livestock in Saudi Arabia, 2010 to 2013. Euro Surveill. 2013;18:20659.
13. Meyer B, Müller MA, Corman VM, Reusken CB, Ritz D, Godeke GJ, et al. Antibodies against MERS coronavirus in dromedary camels, United Arab Emirates, 2003 and 2013. Emerg Infect Dis. 2014;20:552-9. http://dx.doi.org/10.3201/eid2004.131746

Address for correspondence; Malik Peiris, School of Public Health, The University of Hong Kong, 21 Sassoon Rd, Pokfulam, Hong Kong Special Administrative Region; email: malik@hku.hk; or Abdelmohsen Alnaeem, Department of Clinical Studies, College of Veterinary Medicine, King Faisal University, Saudi Arabia; email: aaalnaeem@kfu.edu.sa

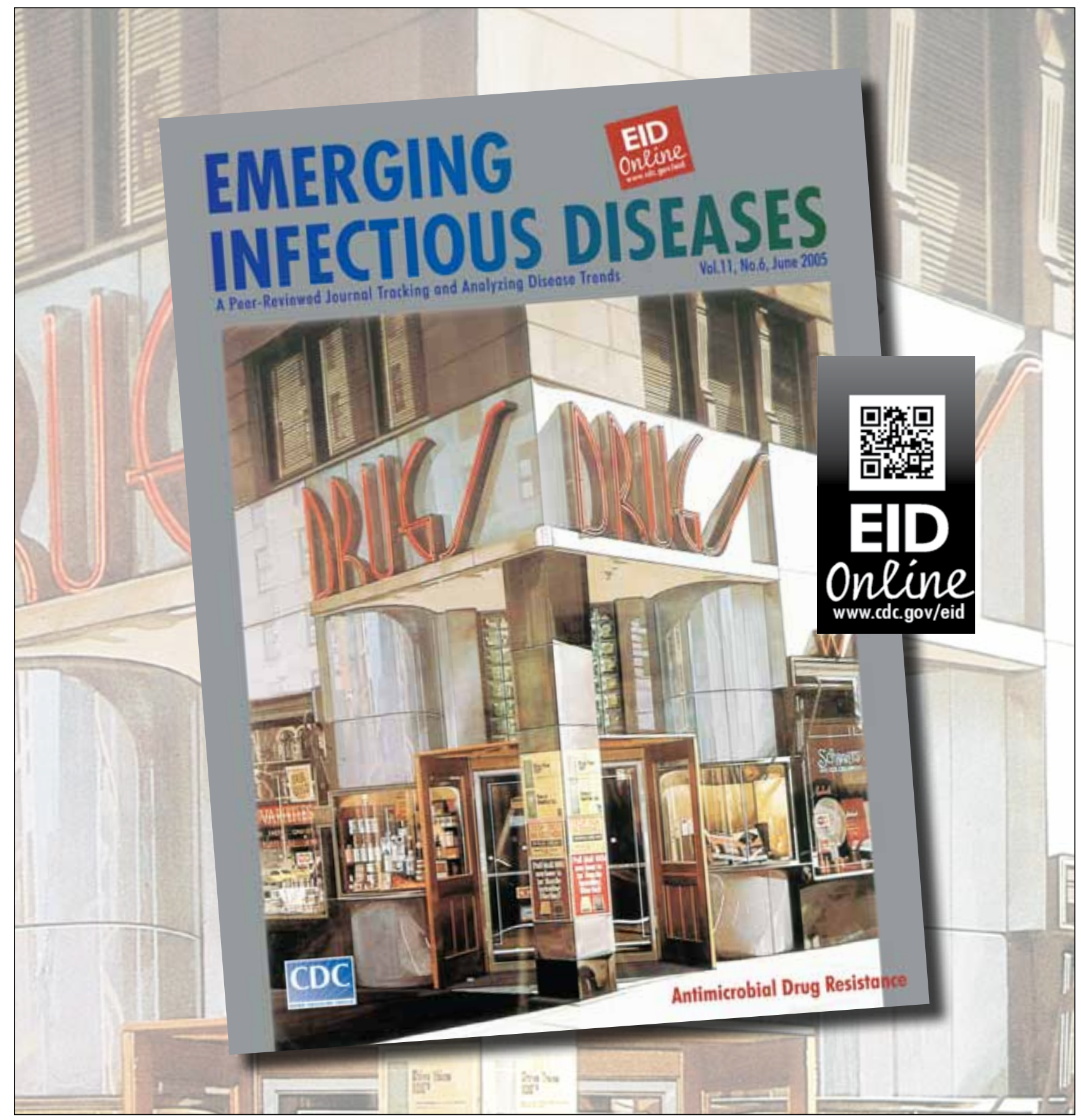

